\title{
Television Viewing at Mealtime Reduces Caloric Compensation in Peripubertal, But Not Postpubertal, Girls
}

\author{
BARKHA P. PATEL, NICK BELLISSIMO, SCOTT G. THOMAS, JILL K. HAMILTON, AND G. HARVEY ANDERSON
}

Department of Nutritional Sciences [B.P.P., G.H.A.], University of Toronto, Ontario M5S 3E2, Canada; Department of Applied Human Nutrition [N.B.], Mount Saint Vincent University, Halifax, Nova Scotia B3M 2J6, Canada; Department of Paediatrics [J.K.H.], Hospital for Sick Children, University of Toronto, Toronto, Ontario M5G 1X8, Canada; Department of Exercise Sciences [S.G.T.], University of

Toronto, Toronto, Ontario M5S 2W6, Canada

\begin{abstract}
The effect of television viewing (TVV) and pubertal status of 9- to 14-y-old girls on mealtime food intake (FI) after a premeal glucose drink was determined. On four separate mornings, girls randomly received equally sweetened drinks containing Sucralose (control) or glucose $(1.0 \mathrm{~g} / \mathrm{kg}$ body weight) in $250 \mathrm{~mL}$ of water $2 \mathrm{~h}$ after a standardized breakfast. FI from an ad libitum pizza meal was measured $30 \mathrm{~min}$ later with or without TVV. Appetite was measured at $15 \mathrm{~min}$ intervals to lunch and postmeal. TVV at mealtime had no effect on FI, however, glucose suppressed FI more with no TVV compared with TVV (24 versus $10 \%, p<0.001)$, primarily because of its effect in peripubertal girls $(p<0.028)$. In postpubertal girls $(n=8)$, glucose reduced FI by $\sim 27 \%$ in both the no TVV and TVV conditions, but in peripubertal girls $(n=17)$, reduction in FI was $22 \%$ without TVV and only $1 \%$ while TVV. Appetite correlated with FI at 30 min only in postpubertal girls. TVV at mealtime reduced caloric compensation after consumption of the glucose drink in peripubertal, but not postpubertal, girls, with no effect on mealtime FI. (Clinical trial number NCT01025687.) (Pediatr Res 70: 513-517, 2011)
\end{abstract}

$\mathrm{F}$ ood intake (FI) regulation in children is influenced by both physiological and environmental factors. Physiological signals of satiety and satiation are primary regulators of FI and energy balance (1). However, many nonfood-related stimuli in the mealtime environment impact this regulation (2). In children, excessive screen time $\left(4^{+} \mathrm{h} / \mathrm{d}\right)$ has been associated with increased incidence of obesity (3). Possible causes of this association are increased preference for energy dense foods and sweetened beverages (4), decreased resting metabolic rate (5), meal skipping (6), and reduced activity (7) while television viewing (TVV).

Despite the strong associations found between obesity and TVV (7), few studies in children and adolescents have reported quantitative FI while TVV using a within-subject design. Although 3- to 5-y olds eat less while TVV (8), 15- to 16-y olds show no differences in FI when eating while TVV, no TVV, and listening to music (9). Only one study examined the effect of TVV on FI in 9- to 14-y-old children (10). Although TVV, boys ate $24 \%$ more at a pizza meal, indicating delayed satiation and showed diminished response to satiety

Received September 9, 2010; accepted May 10, 2011.

Correspondence: G. Harvey Anderson, Ph.D., Department of Nutritional Sciences, Faculty of Medicine, University of Toronto, 150 College Street, M5S 3E2, Toronto, ON, Canada; e-mail: harvey.anderson@utoronto.ca

Supported by an operating grant from the Canadian Institute of Health Research (CIHR; grant MOP-82728).

The authors report no conflicts of interest. signals after a glucose drink taken $30 \mathrm{~min}$ before the meal. Thus, mealtime TVV impaired physiologic signals leading to both satiety and satiation (10).

The effect of TVV on satiety and satiation has not been reported for 9- to 14-y-old girls. Girls in this age range experience hormonal changes during puberty that may impact energy intake (11) and may use food and diet to address their negative perceptions of body image (12). Thus, our objective was to investigate the effect of TVV while eating and pubertal status on subjective appetite and mealtime FI 30 min after consumption of glucose $(1.0 \mathrm{~g} / \mathrm{kg}$ body weight) or noncaloric sweetened drink in 9- to 14-y-old girls. Our hypothesis was that TVV reduces the effect of subjective feelings of satiety arising from a glucose drink and increases mealtime FI in peripubertal and postpubertal girls.

\section{METHODS}

Subjects. Girls aged 9-14 y participated. The Human Subjects Review Committee, University of Toronto Canada, Toronto District School Board, and Toronto Catholic District School Board approved this study. Study population and recruitment strategies were similar to those reported previously (10,13-15). A screening was scheduled for the eligible child and parent at the Department of Nutritional Sciences where informed written consent was obtained from the parent and written assent from the child. Height (m) and weight $(\mathrm{kg})$ were measured, and age-and-sex specific BMI percentiles were calculated according to the Canadian terminology (16) of the CDC and Prevention 2000 growth charts (17). Body fat content (\%) was estimated by measures of triceps, biceps, suprailial and subscapular skinfold thickness (mm) using Harpenden skinfold calipers (Cambridge Scientific Industries, Cambridge, MD). The sum of four skinfold measurements was used to estimate percent fat mass from age- and sex- specific regression equations (18), as previously described (10,13-15). Girls who began menstruating were categorized as postpubertal, whereas all other girls were categorized as peripubertal. Girls were familiarized with visual analog scale (VAS) questionnaires used in the study and asked to select the type of pizza they would like to eat during test visits.

Study design. A within-subject, repeated measures design was used to examine FI after either the glucose or control drink, with or without TVV. Girls were randomly assigned to a treatment order, which was counterbalanced. On four separate mornings, $7 \mathrm{~d}$ apart, girls were given equally sweetened drinks of a SPLENDA Sucralose control or $1.0 \mathrm{~g} / \mathrm{kg}$ body weight glucose in $250 \mathrm{~mL}$ of water, $2 \mathrm{~h}$ after a standardized breakfast of Parmalat fat-free skim milk $(250 \mathrm{~mL}$, $91 \mathrm{kcal}$ ), Honey Nut Cheerios ( $26 \mathrm{~g} ; 103 \mathrm{kcal}$ donated by General Mills, Inc.) and Tropicana Orange Juice ( $236 \mathrm{~mL}, 110 \mathrm{kcal})$. Thirty minutes after drink consumption, girls were provided with an ad libitum pizza lunch, with or without TVV for $45 \mathrm{~min}$, and instructed to eat until comfortably full. In the TVV condition, the program Hannah Montana started simultaneously with the placement of a pizza tray in front of the subjects.

Abbreviations: FI, food intake; PFC, prospective food consumption; TVV, television viewing; VAS, visual analogue scales 
Protocol. Procedures are similar to those reported previously (10,13-15). Girls arrived at the Department between 0900 and $1200 \mathrm{~h}, 2 \mathrm{~h}$ after consuming the standardized breakfast at home. VAS was used to measure subjective feelings assessing motivation-to-eat and physical comfort and were administered at baseline $(0 \mathrm{~min})$, at regular intervals premeal and immediately postmeal. Sweetness and palatability of test beverages/pizza lunch VAS were administered immediately after drink consumption or postmeal. Motivationto-eat VAS, which measure dimensions of subjective appetite (19), was composed of four questions as follows: 1) How strong is your desire to eat? ("very weak" to "very strong"), 2) How hungry do you feel? ("not hungry at all" to "as hungry as I've ever felt"), 3) How full do you feel? ("not full at all" to "very full"), and 4) How much food do you think you can eat? [prospective food consumption (PFC)] ("nothing at all" to "a large amount") (10,13-15). Girls were instructed to read each question and place an " $X$ " along the 100-mm line depending on their current feelings. Physical comfort was assessed by "How well do you feel?" ("not well at all" to "very well"). Sweetness and palatability VAS were formatted similarly $(10,13-15)$.

Two equally sweetened drinks were used. One contained $1.0 \mathrm{~g} / \mathrm{kg}$ body weight glucose monohydrate (Grain Process Enterprises, Toronto, ON, Canada) and the other was a control drink, matched for sweetness and flavor by addition of the high-intensity sweetener SPLENDA Sucralose (donated by Tate and Lyle Sucralose, Inc., Deautur, IL), because it is not metabolized in the body and does not alter blood glucose or insulin secretion (20). Aspartame-sweetened, orangeflavored crystals (1.1 g; Sugar Free Kool-Aid, Kraft Canada Inc., Don Mills, ON, Canada) were added to each drink to standardize flavor. Drinks were prepared $1 \mathrm{~d}$ before consumption in covered, opaque cups and stored in the refrigerator. The following morning, subjects consumed the chilled drinks, followed by $50 \mathrm{~mL}$ of water to minimize aftertaste. After drink consumption, girls were engaged in child-appropriate entertainment (cards, board games, etc.). Thirty minutes after drink consumption, subjects were escorted to a feeding room with individual cubicles and served an ad libitum pizza lunch along with a $500 \mathrm{~mL}$ bottle of water (Danone Crystal Springs) for $45 \mathrm{~min}$.

Girls were asked to remain seated for the $45 \mathrm{~min}$ duration and were instructed to eat until "comfortably full." A freshly baked tray of pizza was provided every $15 \mathrm{~min}$ starting $30 \mathrm{~min}$ after drink consumption. Two varieties of Deep 'N Delicious 5" diameter pizza ( $200 \mathrm{kcal}$ each) were used; pepperoni and three cheese pizzas were donated by McCain (McCain Foods Ltd, Florenceville, NB, Canada). Each tray contained three pizzas: two of their first choice and one of their second choice. Cooked pizzas were weighed and cut into four equal pieces before serving, and the amount left after the meal was subtracted from the initial weight to measure FI. Each variety of pizza was weighed separately, and energy consumed (in kcal) was calculated using manufacturer information. Bottled water was weighed before and after the meal to calculate the net amount ingested. Postmeal, girls rated their appetite, physical comfort, and pleasantness of the meal.

During each of the TVV conditions, while eating, girls watched two of four episodes of Hannah Montana (Vol 01, Livin' The Rock Star Life! Walt Disney Studios Home Entertainment) on a 15" liquid crystal display television (Sharp Aquos, model number: LC-15B6U; Mahwah, NJ). Headphones were provided (Sony, model number: MDR-V250) to prevent distraction from other girls in adjacent cubicles. Each child watched, in random order, all four shows during the study. TV programs excluded food messages and advertisements and were on only during mealtime. After the two TVV conditions, children filled out a TVV VAS to assess their enjoyment of the program with the following question: "How well did you enjoy the program?" ("not well at all" to "very well").

Eating behavior assessment. The Dutch Eating Behavior Questionnaire was administered to assess restrained eating (scores range from 1.0 to 2.4) (21). Younger participants received assistance if they had difficulty interpreting the questionnaire's language.

Statistical analyses. One-tailed tests were used to determine differences in baseline subject characteristics between groups because we hypothesized $a$ priori that age, body weight, height, BMI percentile, fat mass, fat free mass, and restraint would be significantly higher in postpubertal versus peripubertal girls. Food and water intake, physical comfort, and palatability of the meal were analyzed using a within-subjects repeated measures $3 \times 2$ factorial design using the PROC MIXED procedure with drink (control versus glucose), TVV (no TVV versus TVV), and pubertal status (peripubertal versus postpubertal) as main factors. Within the peripubertal and postpubertal girls, a repeated measures $2 \times 2$ factorial design using the PROC MIXED procedure with drink (control versus glucose) and TVV (no TVV versus TVV) was used. Caloric compensation, which is the amount of food compensated for after the caloric drink, was assessed using a paired two-tailed $t$ test. Subjective appetite (reported as the change from baseline) was split into premeal $(0-30$ $\mathrm{min})$ and postmeal $(30-75 \mathrm{~min})$ periods. The premeal period was assessed using drink, pubertal status, and time as factors. TVV was not included in the premeal model as TVV occurred at mealtime only. The postmeal period was assessed using drink, TVV, and pubertal status as factors. Drink palatability and sweetness, and TVV enjoyment were assessed using drink and pubertal status as factors. Post hoc analysis by the Tukey-Kramer test was performed when treatment effects were found to be statistically significant.

An average appetite score was calculated at each time of measurement for each drink treatment by the formula as follows:

Appetite score $=[$ desire to eat + hunger $+(100-$ fullness $)+$ PFC $] / 4$, which reflects the four questions on the motivation-to-eat VAS as used previously (22-25). FI was determined from the total energy content of the pizza consumed at the meal. Cumulative energy intake was calculated from the sum of calories from the drink and meal. Percent caloric compensation was calculated for each person by the following formula $(10,13,26)$ : Compensation $(\%)=[$ control intake $(\mathrm{kcal})-$ treatment intake $(\mathrm{kcal}) / \mathrm{kcal}$ in treatment drink] $\times 100$.

Data are presented as means \pm SEM. Significance was considered at $p<$ 0.05 . Correlations on dependent measures were conducted by use of Pearson correlation coefficients. Statistical Analysis Software (SAS) version 9.2 (SAS Institute Inc., Carey, NC) was used for statistical analyses.

\section{RESULTS}

Subjects. Twenty-five girls participated (Table 1). Twentyone girls were between the 15th and 85th (normal weight), three were between the 85th and 95th (overweight), and one was greater than the 95th (obese) age- and sex- specific BMI percentiles $(16,17)$.

Food and water intake. Drink $(p<0.001)$, but not TVV or pubertal status affected FI at the meal (Table 2). There was a drink-by-pubertal status interaction $(p=0.028)$, explained by a 27\% reduction in FI by glucose in postpubertal girls but only $12 \%$ in peripubertal girls, independent of TVV (Fig. 1A). There were no correlations between BMI or TV program enjoyment and FI. Cumulative energy intake was not affected by drink, TVV, or pubertal status (Table 2). Water intake was not affected by glucose or TVV, but was greater in postpubertal versus peripubertal, girls (Table $2 ; p<0.001$ ).

In peripubertal girls $(n=17)$, there was an interaction between the glucose drink and TVV $(p<0.017)$, demonstrated by a $22 \%$ reduction in FI in the no TVV condition and only a $1 \%$ reduction in the TVV condition (Table 3, Fig. 1B). Cumulative energy intake in peripubertal girls was not affected by drink or TVV alone, but there was a drink-by-TVV interaction (Table 3; $p=$ 0.017). However, post hoc analysis was unable to detect significant differences between treatments.

In postpubertal girls $(n=8)$, glucose reduced FI by $\sim 27 \%$ $(p<0.002)$ in both the no TVV and TVV conditions with no interaction between drink and TVV (Table 3). Cumulative

Table 1. Baseline characteristics of test subjects*

\begin{tabular}{lrcr}
\hline \multicolumn{1}{c}{ Characteristics } & \multicolumn{1}{c}{ All girls } & Peripubertal & Postpubertal \\
\hline Age (y) & $11.5 \pm 0.4$ & $10.4 \pm 0.2 \dagger$ & $13.8 \pm 0.1$ \\
Body weight $(\mathrm{kg})$ & $42.1 \pm 2.2$ & $36.3 \pm 1.7 \dagger$ & $54.3 \pm 2.3$ \\
Height $(\mathrm{cm})$ & $148.8 \pm 2.1$ & $143.4 \pm 1.8 \dagger$ & $160.3 \pm 1.7$ \\
BMI percentile & $55.8 \pm 5.2$ & $50.8 \pm 6.4$ & $66.3 \pm 8.3$ \\
Fat mass $\ddagger(\%)$ & $26.7 \pm 0.9$ & $25.5 \pm 1.0 \dagger$ & $29.2 \pm 1.5$ \\
Fat-free mass (\%) & $73.3 \pm 0.9$ & $74.5 \pm 1.0 \dagger$ & $70.8 \pm 1.5$ \\
Restrained eating§ & $1.5 \pm 0.1$ & $1.3 \pm 0.1 \dagger$ & $1.7 \pm 0.2$ \\
\hline
\end{tabular}

* Data are presented as means \pm SEM. $(n=25$; postpubertal, $n=8$ and peripubertal, $n=17$ ).

$\dagger$ Significantly different from postpubertal by unpaired $t$ test $(p<0.05)$.

$\$$ Fat mass determined from the sum of skinfold measurements at four points (18).

$\S$ Restrained eating was measured with the Dutch Eating Behavior Questionnaire (21). 
Table 2. Effect of glucose drink, TVV and pubertal status on FI, cumulative energy intake, and water intake*

\begin{tabular}{|c|c|c|c|c|c|c|}
\hline & \multicolumn{2}{|c|}{ Drink } & \multicolumn{2}{|c|}{ TVV } & \multicolumn{2}{|c|}{ Pubertal status } \\
\hline & Control & Glucose & No TVV & TVV & Peripubertal & Postpubertal \\
\hline Food intake $\dagger(\mathrm{kcal})$ & $940 \pm 39$ & $779 \pm 31$ \$ & $835 \pm 36$ & $884 \pm 39$ & $845 \pm 33$ & $891 \pm 44$ \\
\hline Cumulative energy intake§ (kcal) & $940 \pm 39$ & $948 \pm 32$ & $919 \pm 33$ & $968 \pm 39$ & $917 \pm 33$ & $1000 \pm 38$ \\
\hline Water intake $\|(\mathrm{g})$ & $208 \pm 23$ & $208 \pm 22$ & $223 \pm 22$ & $194 \pm 23$ & $146 \pm 16$ & $341 \pm 23 \ddagger$ \\
\hline
\end{tabular}

* Data are means \pm SEM; $(n=25)$. A three-factor ANOVA for FI, cumulative energy intake, and water intake was used with drink, TVV, and pubertal status as main factors.

$\dagger$ Food intake was affected by drink $(p<0.001)$, but not TVV $(p=0.194)$ or pubertal status $(p=0.595)$ and a drink-by-pubertal status interaction $(p=0.028)$.

\$ Significantly different $(p<0.001)$.

$\S$ Energy from drink plus energy from test meal intake. Cumulative energy intake was not affected by drink $(p=0.778)$, TVV $(p=0.268)$ or pubertal status $(p=0.360)$ or by interactions among the factors $(p>0.05)$.

$\|$ Water intake at the pizza meal was not affected by drink $(p=0.932)$ TVV $(p=0.278)$ but was affected by pubertal status $(p<0.001)$.
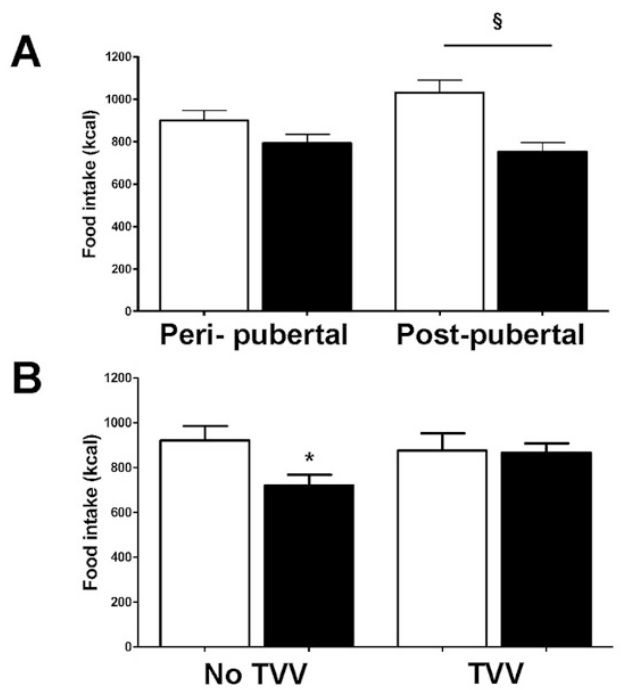

Figure 1. Interaction between drink composition ( $\square$ : control; $\mathbf{\square}$ : glucose). (A) pubertal status and $(B)$ TVV in peripubertal girls. §Significantly different from postpubertal (glucose); *significantly different from all other treatments (Tukey-Kramer post hoc test, $p<0.005)$. Values are mean $\pm \operatorname{SEM}(n=17$, peripubertal; $n=8$, postpubertal).

energy intake in postpubertal girls was not affected by drink or TVV, and there was no interaction between them (Table 3). In the no TVV condition, caloric compensation was 139 and $125 \%$ in the peripubertal and postpubertal girls, respectively, whereas during TVV, caloric compensation was 16 and $127 \%$ in the peripubertal and postpubertal girls, respectively (Table 4).

Subjective appetite scores. Average appetite (Fig. 2), desire-to-eat, hunger, and PFC scores increased over time $(p<$ $0.001)$ in the premeal $(0-30 \mathrm{~min})$ period but were not affected by drink or pubertal status. Postmeal $(75 \mathrm{~min})$ minus premeal (30 min) average appetite means were reduced by the meal but were not affected by drink ( $-44 \pm 4$ versus $-46 \pm 4$; control versus glucose), TVV ( $-46 \pm 4$ versus $-44 \pm 4$; no TVV versus TVV), or pubertal status $(-47 \pm 4$ versus $-41 \pm 3$; peripubertal versus postpubertal). Similarly, desire-to-eat, hunger, and PFC scores were reduced by the meal but were not affected by drink, TVV, or pubertal status.

Fullness was affected by time ( $p<0.001$, data not shown), and there was a trend for a decrease in fullness by glucose $(p=0.062)$ compared with control drink. A time-by-pubertal status interaction showed that postpubertal girls had a lower
Table 3. Effect of glucose drink and TVV on FI and cumulative energy intake in peripubertal and postpubertal girls*

\begin{tabular}{|c|c|c|c|c|}
\hline & \multicolumn{2}{|c|}{ Drink } & \multicolumn{2}{|c|}{ TVV } \\
\hline & Control & Glucose & No TVV & TVV \\
\hline \multicolumn{5}{|l|}{ Peripubertal girls } \\
\hline Food intake $\dagger(\mathrm{kcal})$ & $897 \pm 50$ & $792 \pm 42 \ddagger$ & $819 \pm 43$ & $870 \pm 50$ \\
\hline $\begin{array}{l}\text { Cumulative energy } \\
\text { intake§ (kcal) }\end{array}$ & $897 \pm 50$ & $937 \pm 43$ & $892 \pm 40$ & $942 \pm 52$ \\
\hline \multicolumn{5}{|l|}{ Postpubertal girls } \\
\hline Food intake $\|(\mathrm{kcal})$ & $1030 \pm 60$ & $753 \pm 42 \ddagger$ & $868 \pm 66$ & $915 \pm 58$ \\
\hline $\begin{array}{l}\text { Cumulative energy } \\
\text { intakeII (kcal) }\end{array}$ & $1030 \pm 60$ & $970 \pm 46$ & $976 \pm 58$ & $1024 \pm 49$ \\
\hline
\end{tabular}

* Data are means $\pm \mathrm{SEM} ;(n=17$; peripubertal, $n=8$; postpubertal). A two-factor ANOVA for FI and cumulative energy intake was used with drink and TVV as main factors.

$\dagger$ Food intake in the peripubertal girls was affected by drink $(p=0.02)$, but not TVV $(p=0.388)$ and a drink-by-TVV interaction $(p=0.017)$.

\$ Significantly different $(p<0.05)$.

$\S$ Energy from drink plus energy from test meal intake. Cumulative energy intake in peripubertal girls was not affected by drink $(p=0.374)$ and TVV $(p=0.388)$, but there was a drink-by-TVV interaction $(p=0.017)$.

$\|$ Food intake in the postpubertal girls was affected by drink $(p=0.002)$, but not by TVV $(p=0.167)$ or a drink-by-TVV interaction $(p=0.968)$.

If Energy from drink + energy from test meal. Cumulative energy intake in postpubertal girls was not affected by drink $(p=0.295)$ and TVV $(p=0.167)$, or a drink-by-TVV interaction $(p=0.968)$.

Table 4. Caloric compensation (\%) in peripubertal and postpubertal girls*

\begin{tabular}{lcrc}
\hline & No TVV & TVV & $p$ \\
\hline Peripubertal girls & $139 \pm 31$ & $16 \pm 40$ & 0.025 \\
Postpubertal girls & $125 \pm 36$ & $127 \pm 22$ & 0.973 \\
\hline
\end{tabular}

$*$ Data are means \pm SEM; $(n=17$; peripubertal, $n=8$; postpubertal $)$. Paired $t$ test used between caloric compensation in the no TVV vs TVV condition. Caloric compensation $=[(\mathrm{kcal}$ consumed at the test meal after control drink - kcal consumed at the test meal after glucose drink $) /(\mathrm{kcal}$ in glucose drink)] $\times 100 \%$.

feeling of fullness at 30 versus $15 \mathrm{~min}(p<0.001)$. No factors affected fullness postmeal.

Subjective ratings of physical comfort, sweetness, pleasantness, and enjoyment of the TV program. There were no main effects of drink, TVV, or pubertal status on physical comfort and pleasantness of the meal and no effect of drink and pubertal status on pleasantness and sweetness of the drink (data not shown). However, TV program enjoyment was affected by pubertal status, with peripubertal girls rating the programs $31 \%$ higher than postpubertal girls $(p=0.005)$, but not by drink or drink-by-pubertal status. 


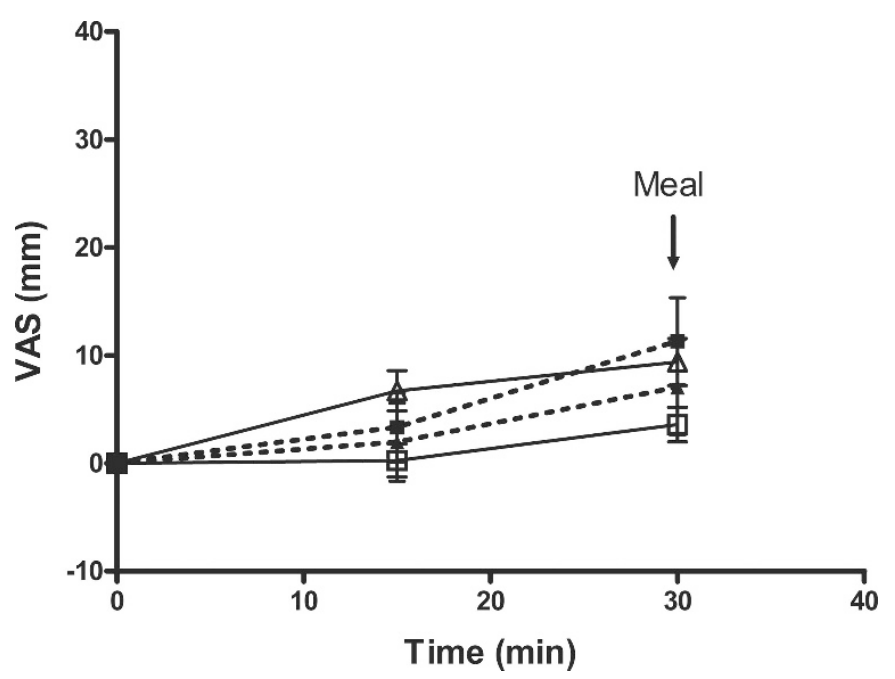

Figure 2. Effect of drink, pubertal status, and time on premeal average appetite. Conditions were control, postpubertal (ם); glucose, postpubertal $(\boldsymbol{\Delta})$; control, peripubertal $(\square)$; and glucose, peripubertal $(\triangle)$. Time affected average appetite (three-way ANOVA, Tukey-Kramer post hoc test, $p<$ $0.001 ; n=17$, peripubertal; $n=8$, postpubertal).

Associations between subjective appetite and FI. In peripubertal girls, average appetite, desire-to-eat, hunger, fullness, and PFC were not associated with FI at $30 \mathrm{~min}$. In postpubertal girls, average appetite $(r=0.74, p=0.037)$, desire-to-eat $(r=0.85$, $p=0.007)$, and hunger $(r=0.76, p=0.027)$ were positively associated with FI at $30 \mathrm{~min}$, whereas $\mathrm{PFC}(r=0.46, p=0.247)$ and fullness $(r=-0.38, p=0.348)$ were not.

\section{DISCUSSION}

Overall, TVV had no effect on FI at the pizza meal. However, in peripubertal girls, TVV in the mealtime environment prevented the reduction in FI after the glucose drink.

Lower lunchtime FI $30 \mathrm{~min}$ after glucose in the no TVV condition is consistent with studies in normal weight adult men (24) and children (10,13-15). However, there may be several explanations for why peripubertal, but not postpubertal, girls failed to decrease FI after the glucose drink while TVV. First, both age and puberty may be factors. Postpubertal girls had an average age of $13.8 \mathrm{y}$ compared with $10.4 \mathrm{y}$ in peripubertal girls, and responded similar to 15 - to 16-y olds, in which no significant differences were found in FI between TVV, no TVV, and listening to music (9). Reduction in FI after glucose was more robust in postpubertal girls, indicating they may have a stronger physiological response to satiety signals than peripubertal girls. Furthermore, with the onset of puberty, estrogen exerts physiological functions including affecting FI regulation and the action of intake regulatory hormones including ghrelin and cholecystokinin (CCK) (27). In rats, estradiol increases CCK's satiating effects $(28,29)$ and attenuates ghrelin's orexigenic effects $(30)$, leading to lower FI. Energy intake is decreased in the follicular compared with the luteal phase of the menstrual cycle because of higher levels of estrogen (31), which may have contributed to the greater reduction in FI in postpubertal girls after glucose. Although we did not account for menstrual cycle phase, we were not powered to evaluate the effects of FI and phase with the current study design.
In contrast to the decrease in FI after glucose in both groups in the no TVV condition, appetite did not decrease and fullness did not increase in either peripubertal or postpubertal girls, which is consistent with other reports in children $(10,13,15,22)$. Although this may suggest that children are unable to accurately reflect their feelings of appetite using VAS, they consistently report reductions in desire-to-eat, hunger, and PFC and increased fullness after the test meal $(10,13,22)$. Because average appetite, desire-to-eat and hunger were positively associated with FI at $30 \mathrm{~min}$ in postpubertal girls only, it can be suggested that subjective appetite is a learned association with FI in postpubertal girls but peripubertal girls are yet unable to make this association (32). However, fullness was not correlated to FI at $30 \mathrm{~min}$, suggesting this measure may be a weak predictor of FI in girls.

Surprisingly, TVV did not delay satiation in either peri- or postpubertal girls, which is in contrast to the higher energy intakes observed in 9- to 14-y-old boys (10), undergraduate students (33), and women who watch TV during mealtime (2). This latter effect of TVV is attributed to diminished awareness of the amount of food consumed (34) as a result of disrupted cognitive restraint (35) and habituation to food cues (36).

Cognitive restraint may have been a factor in postpubertal girls, because scores were significantly greater compared with peripubertal girls. Restraint affects satiation through restriction of FI as a means of controlling body weight (37). Self-regulation of FI is evident after menarche in 12- to 17-y-old girls, who limit their FI because of the concerns with body image (12). Although restraint associates with reduced FI in adult females (38) and restraint was higher in postpubertal girls, its role is unclear because no correlation was found between restraint and FI. Similarly, restraint does not explain why TVV did not delay satiation in peripubertal girls. An alternative explanation may be greater sensitivity to distraction.

TVV as a distraction is known to disrupt habituation to food cues, particularly when there is active engagement in the stimulus (attention allocation), leading to greater energy intakes (36). Consistent with this, TV program enjoyment was higher in peripubertal girls, and children (9-12 y old) ate more of a preferred snack and spent more time eating when watching a continuous TV program that required attention allocation compared with a repeated segment of a program and no TVV (36). Although we did not observe greater FI with TVV in peripubertal girls, distraction may have been a factor in their failure to reduce their FI in response to glucose and at the pizza meal.

Because girls were selected from a relatively large age range and varied considerably in body weight, glucose was provided on a body weight basis. Peripubertal girls and postpubertal girls had an average intake of glucose of 36 and $54 \mathrm{~g}$, respectively. Full compensation for the energy content of the glucose without TVV was found in both peripubertal and postpubertal girls (139 and 125\%, respectively) consistent with previous reports showing children compensate in later meals for sugars consumed as liquids, suggesting that sugars do not bypass physiologic regulatory systems $(39,40)$, unless there are environmental distractions present (10). Although TVV, peripubertal girls compensated by $\sim 9 \mathrm{kcal}$, whereas postpubertal girls compensated by $\sim 276 \mathrm{kcal}$. However, the 
differing amounts of glucose are unlikely to be a factor affecting the differences in the effect of TVV on glucoseinduced FI suppression because neither the number of calories in the glucose drink nor body weight were correlated with caloric compensation after glucose in the TVV condition.

Our study has limitations that are worth noting. First, in place of Tanner staging, we classified girls as peripubertal and postpubertal by the onset of menarche, and as such, may have failed to uncover whether each specific stage (I, II, III, and IV) had any impact on response to the glucose or TVV. Nevertheless, our classification system identified a unique response between the peripubertal and postpubertal girls. Second, the sample size was unbalanced between the two groups. Although only eight postpubertal girls were included in the analysis, there was adequate power $(>80 \%)$ to detect a difference of $\sim 277 \mathrm{kcal}$ between treatments with a SD of $208 \mathrm{kcal}$, supporting the validity of the results observed in the postpubertal group. Third, it is not possible to generalize our results to all TV programs. Finally, these results show that pubertal status is a significant factor to consider when studying the effect of environmental factors on FI control in adolescent girls.

In conclusion, TVV at mealtime reduced caloric compensation after the consumption of a glucose drink in peripubertal, but not postpubertal, girls, but had no effect on satiation as measured by FI at the meal. TV is a modifiable part of the mealtime environment, and further studies are warranted to investigate whether avoidance of mealtime TVV will improve sensitivity to physiologic cues arising from food ingestion during peripubertal development.

Acknowledgment. We thank Monika Constantino for help with the project.

\section{REFERENCES}

1. de Graaf C, Blom WA, Smeets PA, Stafleu A, Hendriks HF 2004 Biomarkers of satiation and satiety. Am J Clin Nutr 79:946-961

2. Bellisle F, Dalix AM, Slama G 2004 Non food-related environmental stimuli induce increased meal intake in healthy women: comparison of television viewing versus listening to a recorded story in laboratory settings. Appetite 43:175-180

3. Crespo CJ, Smit E, Troiano RP, Bartlett SJ, Macera CA, Andersen RE 1988 Television watching, energy intake, and obesity in US children: results from the third National Health and Nutrition Examination Survey-1994. Arch Pediatr Adolesc Med $155: 360-365,2001$

4. Coon KA, Tucker KL 2002 Television and children's consumption patterns. A review of the literature. Minerva Pediatr 54:423-436

5. Klesges RC, Shelton ML, Klesges LM 1993 Effects of television on metabolic rate: potential implications for childhood obesity. Pediatrics 91:281-286

6. Custers K, Van den Bulck J 2010 Television viewing, computer game play and book reading during meals are predictors of meal skipping in a cross-sectional sample of 12-, 14- and 16-year-olds. Public Health Nutr 13:537-543

7. Janssen I, Katzmarzyk PT, Boyce WF, Vereecken C, Mulvihill C, Roberts C, Currie C, Pickett W 2005 Comparison of overweight and obesity prevalence in school-aged youth from 34 countries and their relationships with physical activity and dietary patterns. Obes Rev 6:123-132

8. Francis LA, Birch LL 2006 Does eating during television viewing affect preschool children's intake? J Am Diet Assoc 106:598-600

9. Péneau S, Mekhmoukh A, Chapelot D, Dalix AM, Airinei G, Hercberg S, Bellisle F 2009 Influence of environmental factors on food intake and choice of beverage during meals in teenagers: a laboratory study. Br J Nutr 102:1854-1859

10. Bellissimo N, Pencharz PB, Thomas SG, Anderson GH 2007 Effect of television viewing at mealtime on food intake after a glucose preload in boys. Pediatr Res 61:745-749

11. Rolls BJ, Fedoroff IC, Guthrie JF 1991 Gender differences in eating behavior and body weight regulation. Health Psychol 10:133-142
12. Abraham S, Boyd C, Lal M, Luscombe G, Taylor A 2009 Time since menarche, weight gain and body image awareness among adolescent girls: onset of eating disorders? J Psychosom Obstet Gynaecol 30:89-94

13. Bellissimo N, Desantadina MV, Pencharz PB, Berall GB, Thomas SG, Anderson GH 2008 A comparison of short-term appetite and energy intakes in normal weight and obese boys following glucose and whey-protein drinks. Int J Obes (Lond) 32:362-371

14. Bellissimo N, Thomas SG, Goode RC, Anderson GH 2007 Effect of short-duration physical activity and ventilation threshold on subjective appetite and short-term energy intake in boys. Appetite 49:644-651

15. Bellissimo N, Thomas SG, Pencharz PB, Goode RC, Anderson GH 2008 Reproducibility of short-term food intake and subjective appetite scores after a glucose preload, ventilation threshold, and body composition in boys. Appl Physiol Nutr Metab 33:326-337

16. Dieticians of Canada, Canadian Paediatric Society, College of Family Physicians of Canada, Community Health Nurses Association of Canada 2004 The use of growth charts for assessing and monitoring growth in Canadian infants and children. Can J Diet Pract Res 65:22-32

17. Ogden CL, Kuczmarski RJ, Flegal KM, Mei Z, Guo S, Wei R, Grummer-Strawn LM, Curtin LR, Roche AF, Johnson CL 2002 Centers for Disease Control and Prevention 2000 growth charts for the United States: improvements to the 1977 National Center for Health Statistics version. Pediatrics 109:45-60

18. Brook CG 1971 Determination of body composition of children from skinfold measurements. Arch Dis Child 46:182-184

19. Stubbs RJ, Hughes DA, Johnstone AM, Rowley E, Reid C, Elia M, Stratton R, Delargy H, King N, Blundell JE 2000 The use of visual analogue scales to assess motivation to eat in human subjects: a review of their reliability and validity with an evaluation of new hand-held computerized systems for temporal tracking of appetite ratings. Br J Nutr 84:405-415

20. Duffy VB, Anderson GH 1998 Position of the American Dietetic Association: use of nutritive and nonnutritive sweeteners. J Am Diet Assoc 98:580-587

21. van Strien T, Oosterveld P 2008 The children's DEBQ for assessment of restrained, emotional, and external eating in 7- to 12-year-old children. Int $\mathrm{J}$ Eat Disord 41:72-81

22. Anderson GH, Saravis S, Schacher R, Zlotkin S, Leiter L 1989 Aspartame: effect on lunch-time food intake, appetite and hedonic response in children. Appetite 13:93-103

23. Woodend DM, Anderson GH 2001 Effect of sucrose and safflower oil preloads on short term appetite and food intake of young men. Appetite 37:185-195

24. Anderson GH, Catherine NL, Woodend DM, Wolever TM 2002 Inverse association between the effect of carbohydrates on blood glucose and subsequent short-term food intake in young men. Am J Clin Nutr 76:1023-1030

25. Anderson GH, Woodend D 2003 Effect of glycemic carbohydrates on short-term satiety and food intake. Nutr Rev 61:S17-S26

26. Black RM, Anderson GH 1994 Sweeteners, food intake and selection. In: Fernstrom JD, Miller GD, International Life Sciences Institute (eds) Appetite and Body Weight Regulation: Sugar, Fat, and Macronutrient Substitutes. CRC Press, Boca Raton, pp 125-136

27. Lebenthal Y, Gat-Yablonski G, Shtaif B, Padoa A, Phillip M, Lazar L 2006 Effect of sex hormone administration on circulating ghrelin levels in peripubertal children. J Clin Endocrinol Metab 91:328-331

28. Butera PC, Bradway DM, Cataldo NJ 1993 Modulation of the satiety effect of cholecystokinin by estradiol. Physiol Behav 53:1235-1238

29. Lindén A, Uvnas-Moberg K, Forsberg G, Bednar I, Sodersten P 1990 Involvement of cholecystokinin in food intake: III. Oestradiol potentiates the inhibitory effect of cholecystokinin octapeptide on food intake in ovariectomized rats. J Neuroendocrinol 2:797-801

30. Butera PC 2010 Estradiol and the control of food intake. Physiol Behav 99:175-180

31. Brennan IM, Feltrin KL, Nair NS, Hausken T, Little TJ, Gentilcore D, Wishart JM, Jones KL, Horowitz M, Feinle-Bisset C 2009 Effects of the phases of the menstrual cycle on gastric emptying, glycemia, plasma GLP-1 and insulin, and energy intake in healthy lean women. Am J Physiol Gastrointest Liver Physiol 297:G602-G610

32. de Graaf C, Kok FJ 2010 Slow food, fast food and the control of food intake. Nat Rev Endocrinol 6:290-293

33. Blass EM, Anderson DR, Kirkorian HL, Pempek TA, Price I, Koleini MF 2006 On the road to obesity: television viewing increases intake of high-density foods. Physiol Behav 88:597-604

34. Blundell JE 1995 The psychobiological approach to appetite and weight control. In: Brownell KD, Fairburn CG (eds) Eating Disorders and Obesity: a Comprehensive Handbook. Guilford Press, New York, pp 13-20

35. Bellisle F, Dalix AM 2001 Cognitive restraint can be offset by distraction, leading to increased meal intake in women. Am J Clin Nutr 74:197-200

36. Temple JL, Giacomelli AM, Kent KM, Roemmich JN, Epstein LH 2007 Television watching increases motivated responding for food and energy intake in children. Am J Clin Nutr 85:355-361

37. Bjornelv S, Nordahl HM, Holmen TL 2011 Psychological factors and weight problems in adolescents. The role of eating problems, emotional problems, and personality traits: the Young-HUNT study. Soc Psychiatry Psychiatr Epidemiol 46:353-362

38. Bellisle F, Dalix AM, Airinei G, Hercberg S, Peneau S 2009 Influence of dietary restraint and environmental factors on meal size in normal-weight women. A laboratory study. Appetite 53:309-313

39. Anderson GH, Woodend D 2003 Consumption of sugars and the regulation of short-term satiety and food intake. Am J Clin Nutr 78:843S-849S

40. Birch LL, Deysher M 1986 Caloric compensation and sensory specific satiety: evidence of self-regulation of food intake by young children. Appetite 7:323-331 